\title{
Randomized controlled trial comparing outcomes of video capsule endoscopy with push enteroscopy in obscure gastrointestinal bleeding
}

\author{
Dev S Segarajasingam MBBS FRACP ${ }^{1}$, Stephen C Hanley MD PhD ${ }^{2}$, Alan N Barkun MDCM FRCPC MSc ${ }^{3,4}$, \\ Kevin A Waschke MDCM FRCPC ${ }^{3}$, Pascal Burtin MD ${ }^{5}$, Josée Parent MDCM FRCPC ${ }^{3}$, Serge Mayrand MDCM FRCPC ${ }^{3}$, \\ Carlo A Fallone MDCM FRCPC ${ }^{3}$, Gilles Jobin MD ${ }^{6}$, Ernest G Seidman MDCM FRCPC ${ }^{3}$, Myriam Martel BSc ${ }^{3}$
}

\begin{abstract}
DS Segarajasingam, SC Hanley, AN Barkun, et al. Randomized controlled trial comparing outcomes of video capsule endoscopy with push enteroscopy in obscure gastrointestinal bleeding. Can J Gastroenterol Hepatol 2015;29(2):85-90.
\end{abstract}

BACKGROUND: Optimal management of obscure gastrointestinal bleeding (OGIB) remains unclear.

OBJECTIVE: To evaluate diagnostic yields and downstream clinical outcomes comparing video capsule endoscopy (VCE) with push enteroscopy (PE).

METHODS: Patients with OGIB and negative esophagogastroduodenoscopies and colonoscopies were randomly assigned to VCE or PE and followed for 12 months. End points included diagnostic yield, acute or chronic bleeding, health resource utilization and crossovers. RESULTS: Data from 79 patients were analyzed (VCE $n=40 ;$ PE $\mathrm{n}=39 ; 82.3 \%$ overt OGIB). VCE had greater diagnostic yield $(72.5 \%$ versus $48.7 \%$; $\mathrm{P}<0.05$ ), especially in the distal small bowel ( $58 \%$ versus $13 \% ; \mathrm{P}<0.01$ ). More VCE-identified lesions were rated possible or certain causes of bleeding $(79.3 \%$ versus $35.0 \%$; $\mathrm{P}<0.05)$. During follow-up, there were no differences in the rates of ongoing bleeding (acute $[40.0 \%$ versus 38.5\%; P not significant], chronic [32.5\% versus $45.6 \%$; P not significant]), nor in health resource utilization. Fewer VCE-first patients crossed over due to ongoing bleeding (22.5\% versus 48.7\%; P<0.05).

CONCLUSIONS: A VCE-first approach had a significant diagnostic advantage over PE-first in patients with OGIB, especially with regard to detecting small bowel lesions, affecting clinical certainty and subsequent further small bowel investigations, with no subsequent differences in bleeding or resource utilization outcomes in follow-up. These findings question the clinical relevance of many of the discovered endoscopic lesions or the ability to treat most of these effectively over time. Improved prognostication of both patient characteristics and endoscopic lesion appearance with regard to bleeding behaviour, coupled with the impact of therapeutic deep enteroscopy, is now required using adapted, high-quality study methodologies.

Key Words: Anemia; Enteroscopy; Obscure GI bleeding; Obscure GI hemorrhage; Small bowel bleeding; Videocapsule
Un essai aléatoire et contrôlé comparant les résultats de l'endoscopie par vidéocapsule à l'entéroscopie poussée en cas de saignement gastro-intestinal occulte

HISTORIQUE : On ne connaît pas encore la prise en charge optimale du saignement gastro-intestinal occulte (SGIO).

OBJECTIF : Évaluer le rendement diagnostique et les résultats cliniques en aval de l'endoscopie par vidéocapsule (EVC) par rapport à l'entéroscopie poussée (EP).

MÉTHODOLOGIE : Les patients ayant un SGIO et dont les œsophagogastroduodénoscopies et les coloscopies étaient négatives ont été répartis au hasard entre une EVC ou une EP et suivis pendant 12 mois. Les critères d'évaluation incluaient le rendement diagnostique, le saignement aigu ou chronique, l'utilisation des ressources de santé et les permutations.

RÉSULTATS : Les chercheurs ont analysé les données de 79 patients (EVC n=40; EP n=39; 82,3 \% de SGIO manifeste). L'EVC s'associait au meilleur rendement diagnostique $(72,5 \%$ par rapport à $48,7 \% ; \mathrm{P}<0,05)$, notamment dans l'intestin grêle distal ( $58 \%$ par rapport à $13 \% ; \mathrm{P}<0,01)$. Plus de lésions déterminées par l'EVC étaient classées comme les causes possibles ou établies du saignement $(79,3 \%$ par rapport à $35,0 \% ; \mathrm{P}<0,05)$. Pendant le suivi, il n'y avait pas de différences dans le taux de saignement continu (aigu [40,0 \% par rapport à 38,5\%; P non significatif], chronique [32,5\% par rapport à 45,6\%; P non significatif]) ni dans l'utilisation des ressources de santé. Moins de patients ayant d'abord subi une EVC ont été permutés en raison d'un saignement continu (22,5\% par rapport à $48,7 \% ; \mathrm{P}<0,05)$.

CONCLUSIONS : La décision de commencer par l'EVC comportait un avantage diagnostique important par rapport à l'EP chez les patients ayant un SGIO, notamment pour ce qui est de la détection de lésions de l'intestin grêle, et influait sur la certitude clinique et les examens subséquents de l'intestin grêle, sans différences subséquentes sur les résultats des saignements ou l'utilisation des ressources lors du suivi. Ces observations remettent en question la pertinence clinique de déceler de nombreuses lésions endoscopiques ou d'en traiter la plupart avec efficacité au fil du temps. Il faut désormais poser un meilleur pronostic des caractéristiques des patients et de l'apparence des lésions endoscopiques en regard du comportement du saignement, et tenir compte des effets de l'entéroscopie thérapeutique profonde à l'aide de méthodologies adaptées d'études de haute qualité.

\footnotetext{
$A$ lthough esophagogastroduodenoscopy and colonoscopy provide a Adiagnosis in up to $95 \%$ of cases of gastrointestinal bleeding $(1,2)$, the remaining $5 \%$ experience obscure gastrointestinal bleeding (OGIB). Although relatively rare, OGIB nevertheless prompts significant utilization of health care resources. Reports document an average of up to seven diagnostic tests per patient (3), five hospitalizations and 46 units of blood transfused before definitive diagnosis (4). Further complicating the matter is the debate regarding the optimal imaging modality in the diagnostic workup (5).
}

Video capsule endoscopy (VCE) has been touted as a useful tool for the evaluation of OGIB, and is recommended by several gastroenterology societies - including the American Gastroenterological Association, American Society for Gastrointestinal Endoscopy and European Society of Gastrointestinal Endoscopy - for patients with OGIB after initial negative esophagogastroduodenoscopy and colonoscopy (which can first be repeated in selected cases) $(5,6)$. These recommendations are based on summary evidence that demonstrated VCE to be equivalent or superior to other imaging modalities with respect to diagnostic

${ }^{1}$ Department of Gastroenterology and Hepatology, Sir Charles Gairdner Hospital and School of Population Health, The University of Western Australia, Crawley, Australia; ${ }^{2}$ Division of General Surgery; ${ }^{3}$ Division of Gastroenterology; ${ }^{4}$ Department of Epidemiology, Biostatistics and Occupational Health, McGill University Health Centre, McGill University, Montreal, Quebec; ${ }^{5}$ Endoscopy Unit, Gustave Roussy Institute of Oncology, Villejuif, Greater

Paris, France; ${ }^{6}$ Division of Gastroenterology, Montreal University, Montreal, Quebec

Correspondence: Dr Alan N Barkun, Division of Gastroenterology, McGill University Health Centre, Montreal General Hospital site,

1650 Cedar Avenue, room D16.125, Montréal, Quebec H3G 1A4. Telephone 514-934-8309, fax 514-834-8531, e-mail alan.barkun@muhc.mcgill.ca Received for publication September 11, 2014. Accepted January 14, 2015 
yield in patients with OGIB (7), including individuals presenting with iron deficiency anemia (an occult type of OGIB) (8). A subsequent randomized clinical trial comparing VCE and push enteroscopy (PE) as first-line imaging tests after a negative gastroscopy and colonoscopy demonstrated a greater diagnostic yield for VCE, but similar clinical outcomes at 12 months. The initial VCE strategy was associated with a reduced need for alternative exploration (9). A more recent randomized clinical trial confirmed the diagnostic superiority of VCE over small bowel follow-through, but also showed equivalent clinical outcomes (10). The International Conference on Capsule Endoscopy (11) has recommended further clinical trials to assess the impact of VCE on clinical outcomes.

Accordingly, we performed a randomized controlled trial (RCT) comparing VCE and PE with regard to diagnostic yield and to a series of clinically meaningful bleeding outcomes.

\section{METHODS}

\section{Trial design}

Patients were randomly assigned to VCE or PE, which was the most widely available small bowel endoscopic approach at the time the trial was designed and funding secured.

It was hypothesized that VCE would have a higher diagnostic yield than PE, leading to less acute and/or chronic bleeding than PE over time. Furthermore, it was hypothesized that these improved outcomes would also manifest as resolution of anemia, with less transfusion, hospitalization and surgical intervention rates. Other objectives were to determine the safety profile and crossover rates of the respective imaging modalities.

\section{Study population}

Between March 2006 and December 2009, all consecutive adult ( $\geq 18$ years of age) patients referred to the McGill University Health Centre (Montreal, Quebec) with OGIB were considered for randomization.

OGIB was defined as either overt health care professional-witnessed melena (occult blood-positive black tarry stools) or hematochezia (maroon- or red-coloured stools) within the past six months, associated with an acute drop in hemoglobin level $\geq 15 \mathrm{~g} / \mathrm{L}$ (on two separate blood tests) or occult bleeding (persistent or recurrent iron deficiency anemia [hemoglobin $<100 \mathrm{~g} / \mathrm{L}$ for six months with a mean corpuscular volume $<80 \mu \mathrm{m}^{3}$, hypoferritinemia and iron saturation $<15 \%$ without evidence of associated hematological or inflammatory disease), requiring transfusion or iron supplementation, in the context of repeated fecal occult blood-positive tests (5). At the time of randomization, patients had already undergone negative esophagogastroduodenoscopy, colonoscopy and small bowel follow-through studies.

Exclusion criteria were significant cardiopulmonary disease preventing endoscopic examination, presence of an implanted electromedical device (a contraindication for VCE at the time of trial planning), pregnancy, previous gastrectomy or vagotomy, suspected obstruction or fistula, gastrointestinal motility disorders, intestinal diverticula, extensive Crohn enteritis, contraindication to erythromycin or polyethylene glycol ingestion, or recent VCE or PE examinations. To increase the generalizability of the findings, the use of acetylsalicylic acid, anti-inflammatory, anticoagulant or antiplatelet medications were not among the exclusion criteria.

\section{Procedures}

Procedures (VCE or PE) were undertaken within seven days of randomization. All patients received a $2 \mathrm{~L}$ polyethylene glycol oral preparation solution $12 \mathrm{~h}$ before their study. Patients undergoing small bowel VCE (Given Imaging, Israel) received oral simethicone $80 \mathrm{mg}$ and erythromycin $500 \mathrm{mg}$ before the study. Capsule recording devices were retrieved $8 \mathrm{~h}$ after capsule ingestion. Images were read by a trained technician and all examinations reviewed in their entirety by an experienced physician (EGS). Abdominal radiography was performed within days after the study if the capsule did not reach the cecum and evacuation of the capsule was in doubt. Patients underwent PE under conscious sedation with a standard push videoenteroscope (Olympus Corporation, Japan) passed as far as possible into the small bowel. Photographic documentation of all lesions was performed. The investigator recorded the distance reached by the enteroscope and the presence of any lesions, as well as their location and relation to bleeding (none/possible/certain) using a standardized report sheet specifically designed for the present trial. Therapy was performed consistent with standard of care.

\section{Outcomes}

The primary outcome of the present study was lesion detection rate. Also assessed were lesions deemed to be responsible for OGIB so that the potential implications of the interpretation of detected lesions on clinical end points could be addressed. Principal secondary outcomes included bleeding outcomes at follow-up and study completion. Ongoing (defined as persistent or recurrent bleeding) included acute bleeding (defined as melena, hematochezia or a drop in hemoglobin $>15 \mathrm{~g} / \mathrm{L}$ over $24 \mathrm{~h}$ ) and chronic bleeding (defined as a hemoglobin level $<100 \mathrm{~g} / \mathrm{L}$ or a drop in hemoglobin $>20 \mathrm{~g} / \mathrm{L}$ within one visit, or a drop in hemoglobin $>10 \mathrm{~g} / \mathrm{L}$ over two consecutive visits). Improvement was defined as an increase in hemoglobin over two successive visits in the absence of acute or chronic bleeding. A stable condition was defined as the absence of improvement, acute or chronic bleeding.

Crossovers could only occur after patients had undergone the procedure to which they had been randomly assigned and was dictated by the clinical course. Immediate crossover (before ongoing rebleeding occurred) was permitted only in patients who underwent VCE initially, and had a lesion identified as needing endoscopic therapy.

Other secondary outcomes included diagnostic yield relative to lesion location, health resource utilization including additional imaging procedures, transfusions and iron supplementation, hospitalizations and surgical interventions, and adverse events related to study procedures.

Demographic data were collected at baseline. Follow-up visits occurred every month for six months and again at 12 months. Patients were questioned about OGIB recurrence, transfusion requirements, iron supplementation, hospitalizations and surgical interventions, recent blood tests, crossover and adverse events. Patient satisfaction measures were recorded at baseline and the one-, six- and 12-month visits. Questionnaires for missed visits were completed either by mail or by telephone. Unscheduled visits were also recorded.

\section{Randomization}

Patients were randomly assigned to undergo VCE or PE. Randomization occurred in a 1:1 proportion, stratified according to overt versus occult bleeding as defined above, using serially numbered sealed envelopes and blocks of eight. Due to the nature of the procedures, blinding of patients and treating physicians was not possible. Treating physicians were made aware of the procedure results. The study was approved by the McGill University Institutional Review Board and the study was registered at clinicalgov.com (NCT01424254). All patients provided informed written consent and all authors had access to the study data and had reviewed and approved the final manuscript.

\section{Statistical analysis and sample size}

Based on representative detection rates available at the time of planning of the trial (12), 40 patients in each group were required to demonstrate a significant difference in lesion detection rates with a statistical power of $90 \%$ and an alpha of 0.05 . Descriptive statistics were performed for demographic and clinical characteristics of patients at baseline. Comparisons of outcomes were performed using inferential testing for categorical $\left(\chi^{2}\right.$ test: diagnostic yields, imaging procedures, iron supplementation, hospitalizations, surgical interventions) and continuous variables ( $t$ test: transfusion requirements, hospital length of stay). All statistical analyses were performed using SAS version 9.2 (SAS Institute Inc, USA) and data are presented as mean \pm SD or percentage and $95 \%$ CI. Because of the expected high rate of crossovers in both directions (even if this was only allowed after initial testing), the primary analysis 
TABLE 1

\section{Baseline characteristics}

\begin{tabular}{lcc}
\hline Characteristic & VCE $(\mathbf{n}=40)$ & PE $(\mathbf{n}=\mathbf{3 9})$ \\
\hline Age, years & $68.4 \pm 15.2$ & $68.6 \pm 14.0$ \\
Female sex & $40.0(24.1-55.9)$ & $33.3(17.9-48.8)$ \\
Duration of diagnosis, months & $24.8 \pm 32.7$ & $25.8 \pm 49.6$ \\
Overt bleeding & $82.5(69.5-94.8)$ & $82.1(69.5-94.7)$ \\
Previous investigations, \% & & \\
Esophagogastroduodenoscopy & $1.3 \pm 0.7$ & $1.5 \pm 1.0$ \\
Colonoscopy & $1.5 \pm 0.8$ & $1.8 \pm 1.7$ \\
Small bowel follow-through & 100 & 100 \\
Angiography & $46.2(14.8-77.5)$ & $28.6(1.5-55.6)$ \\
Nuclear scans & $85.0(67.9-100.0)$ & $69.6(49.2-89.9)$ \\
Hemoglobin, g/L & $103 \pm 18$ & $102 \pm 15$ \\
Iron, $\mu$ mol/L & $12 \pm 16$ & $8 \pm 7$ \\
Ferritin, $\mu$ g/L & $69 \pm 84$ & $59 \pm 101$ \\
Transfusions & $5.8 \pm 6.3$ & $8.6 \pm 6.4$ \\
Iron supplementation & $47.5(31.3-36.7)$ & $38.5(22.5-54.4)$ \\
Antiplatelet & $5.0(0.0-12.1)$ & $5.1(0.0-12.4)$ \\
Anticoagulant & $7.5(0.0-16.0)$ & $15.4(3.5-27.2)$ \\
Anti-inflammatory & $2.5(0.0-7.6)$ & $7.7(0.0-16.4)$ \\
Acetylsalicylic acid & $22.5(9.0-36.0)$ & $25.6(11.3-40.0)$ \\
Proton pump inhibitor & $57.5(41.5-73.5)$ & $61.5(45.6-77.5)$ \\
Calcium channel blocker & $27.5(13.0-42.0)$ & $33.3(17.9-48.8)$ \\
Comorbidities & $2.7 \pm 1.4$ & $2.4 \pm 1.8$ \\
\hline Data presented as mean $\pm S D$ & $(95 \%(C 1) * A 1 / p a t e n t s$ \\
\hline
\end{tabular}

Data presented as mean $\pm S D$ or $\%(95 \% \mathrm{Cl})$. *All patients underwent esophagogastroduodenoscopy, colonoscopy and small bowel follow through before enrollment in the present trial. N/A Not applicable; PE Push enteroscopy; VCE Video capsule endoscopy

TABLE 2

Diagnostic yields from video capsule endoscopy (VCE) and push enteroscopy (PE)

\begin{tabular}{lccc}
\hline & VCE $(\mathbf{n}=\mathbf{4 0})$ & PE $(\mathbf{n}=\mathbf{3 9})$ & $\mathbf{P}$ \\
\hline Lesion location & 72.5 & 48.7 & 0.03 \\
Stomach & 17.5 & 33.3 & 0.11 \\
Duodenum & 12.5 & 12.8 & 0.97 \\
Proximal jejunum & 50.0 & 10.3 & $<0.01$ \\
Distal jejunum & 40.0 & 2.6 & $<0.01$ \\
Proximal ileum & 27.5 & $\mathrm{~N} / \mathrm{A}$ & \\
Distal ileum & 32.5 & $\mathrm{~N} / \mathrm{A}$ & \\
Colon & 12.5 & $\mathrm{~N} / \mathrm{A}$ & \\
Lesions per patient, mean $\pm \mathrm{SD}_{\text {Lesion as possible/certain cause }}$ & $1.9 \pm 1.8$ & $0.6 \pm 0.7$ & $<0.01$ \\
Lesion type* $^{*}$ & 79.3 & 35.0 & $<0.01$ \\
Vascular anomaly & & & \\
Ulcer & 65.5 & 36.8 & 0.05 \\
Erosion & 24.1 & 15.8 & 0.49 \\
Mucosal change & 6.9 & 21.1 & 0.15 \\
Polyp/tumour & 17.2 & 15.8 & 0.90 \\
Stricture & 17.2 & 5.3 & 0.22 \\
Diverticulum & 0.0 & 5.3 & 0.22 \\
Celiac disease $^{\dagger}$ & 0.0 & 5.3 & 0.22 \\
Lymphangiectasia $_{\text {Endoscopic therapy }}$ & 3.5 & 0.0 & 0.41 \\
\hline Data resent as & 6.9 & 0.0 & 0.24 \\
\hline
\end{tabular}

Data presented as \% unless otherwise indicated. ${ }^{*}$ The sum of lesion types may exceed $100 \%$ because patients may have been found to have more than one type of lesion; ${ }^{\dagger}$ Not confirmed on subsequent duodenal biopsies or tissue transglutaminase testing. N/A Not applicable

was conducted on an intention-to-treat basis; also performed was an exploratory secondary analysis on a per-protocol basis. A threshold of 0.05 was adopted for statistical significance.

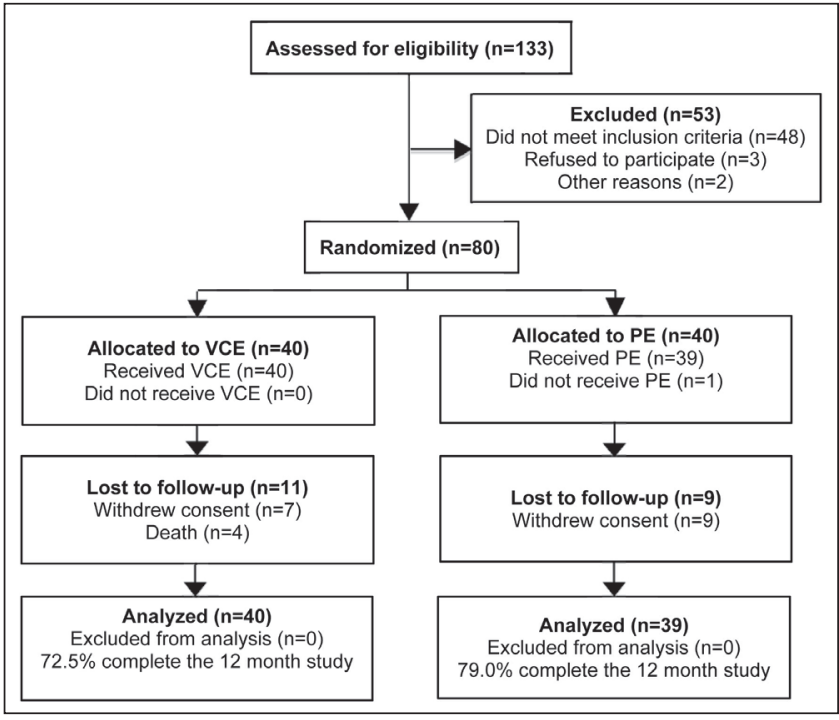

Figure 1) Study flowchart. PE Push enteroscopy; VCE Video capsule endoscopy

Study population

\section{RESULTS}

Enrollment occurred over the first 45 months, starting March 2006, with the final patient completing follow-up in January 2011. Over the study period, 133 patients were assessed and 80 were enrolled, with 40 allocated to each group (Figure 1). One patient randomly assigned to $\mathrm{PE}$ did not undergo $\mathrm{PE}$, underwent no other procedures and was withdrawn from the study. Most $(82.3 \%)$ presented with overt OGIB. Baseline characteristics are presented in Table 1; demographics were comparable between the two groups. Of note, patients had been initially diagnosed with OGIB, on average, $>2$ years before enrollment in the study, and most had undergone extensive endoscopic and imaging studies to ascertain the origin of the bleeding before enrollment (although all required recent evidence of bleeding for enrollment within the past six months, as defined above).

\section{Primary outcome}

Lesion detection rates for initial diagnostic studies (ie, before any potential crossover) are shown in Table 2 . While $\geq 1$ lesions were detected in most patients, VCE detected lesions (regardless of relation to bleeding) in significantly more patients than $\mathrm{PE}(72.5 \%$ versus $48.7 \% ; \mathrm{P}=0.03$ ) and also in significantly more locations per patient $(1.9 \pm 1.8$ versus $0.6 \pm 0.7$, respectively; $\mathrm{P}<0.01)$. Furthermore, while the diagnostic yield was comparable between the two modalities with respect to the stomach and duodenum, more patients had lesions detected in the jejunum by VCE than by PE $(57.5 \%$ versus $12.8 \%$; $\mathrm{P}<0.01$ ). VCE also detected lesions in the ileum and colon (regions not reached by PE) for which no comparisons could be made.

Overall, the lesions identified by VCE were more likely to be deemed causes of bleeding than those identified by $\mathrm{PE}$ (possible/certain: $79.3 \%$ versus $35.0 \%$; $\mathrm{P}=0.01$; certain: $17.2 \%$ versus $0.0 \% ; \mathrm{P}=0.05$ ). The types of lesions identified between the two imaging modalities were comparable.

\section{Secondary outcomes}

Patients were followed for a mean $( \pm$ SD) of $9.6 \pm 4.0$ months (Table 3 ). Over the course of the study, the rates of patients reporting either ongoing acute or chronic bleeding at at least one follow-up visit did not differ between the VCE and PE groups (acute: $40.0 \%$ versus $38.5 \%$; P not significant; chronic: $32.5 \%$ versus $45.6 \%$, respectively; $\mathrm{P}>0.05)$. Patients experienced a mean of $0.9 \pm 1.6$ documented bleeding episodes over the course of the study and, again, this outcome did not differ between VCE and PE patients $(0.8 \pm 1.3$ versus $1.1 \pm 1.9 ; \mathrm{P}>0.05)$. 
TABLE 3

\section{Bleeding rates}

\begin{tabular}{lccc}
\hline Variable & VCE $(\mathbf{n}=\mathbf{4 0})$ & PE $(\mathbf{n}=\mathbf{3 9})$ & $\mathbf{P}$ \\
\hline Follow-up, months, mean \pm SD & $9.8 \pm 4.3$ & $9.5 \pm 3.6$ & 0.23 \\
Any acute bleeding $^{*}$ & 40.0 & 38.5 & 0.89 \\
Any chronic bleeding $^{\dagger}$ & 32.5 & 45.6 & 0.31 \\
Bleeding episodes, mean \pm SD $^{\text {Study completion }}$ & $0.8 \pm 1.3$ & $1.1 \pm 1.9$ & 0.96 \\
Acute bleeding $^{*}$ & 77.5 & 79.5 & 0.73 \\
Chronic bleeding $^{\dagger}$ & 15.0 & 10.3 & 0.53 \\
Stable $_{\text {Improved }}$ & 2.5 & 10.3 & 0.16 \\
Death & 65.0 & 74.4 & 0.37 \\
\hline
\end{tabular}

Data presented as \% unless otherwise indicated. *Defined as melena, hematochezia or a drop in hemoglobin $>15 \mathrm{~g} / \mathrm{L}$ over $24 \mathrm{~h}$; ${ }^{\dagger}$ Defined as a hemoglobin level $<100 \mathrm{~g} / \mathrm{L}$ or a drop in hemoglobin $>20 \mathrm{~g} / \mathrm{L}$ within one visit, or a drop in hemoglobin $>10 \mathrm{~g} / \mathrm{L}$ over two consecutive visits. PE Push enteroscopy; VCE Video capsule endoscopy

\section{TABLE 4}

\section{Health resource utilization}

\begin{tabular}{lccc}
\hline Variable & VCE $(\mathbf{n}=\mathbf{4 0})$ & $\mathbf{P E}(\mathbf{n}=\mathbf{3 9})$ & $\mathbf{P}$ \\
\hline Follow-up, months, mean $\pm \mathrm{SD}$ & $9.8 \pm 4.3$ & $9.5 \pm 3.6$ & 0.23 \\
Hospitalization & 40.0 & 53.9 & 0.22 \\
Hospitalization, days, mean $\pm \mathrm{SD}$ & $9.4 \pm 5.8$ & $11.7 \pm 20.0$ & 0.22 \\
Blood transfusion & 42.5 & 57.9 & 0.17 \\
Blood transfusion, units, mean $\pm \mathrm{SD}$ & $2.8 \pm 4.3$ & $3.0 \pm 5.6$ & 0.65 \\
Iron supplementation & 82.5 & 84.2 & 0.84 \\
Surgical intervention & 5.0 & 5.1 & 0.98 \\
Cross-over & 22.5 & 48.7 & 0.01 \\
\hline
\end{tabular}

Data presented as \% unless otherwise indicated. PE Push enteroscopy; VCE Video capsule endoscopy

Most (78.2\%) patients completed the one-year follow-up period. At study completion, the majority of patients were found to have a 'stable condition' as predefined with respect to their gastrointestinal bleeding $(65.0 \%$ versus $74.4 \%$ for $\mathrm{VCE}$ versus PE; $\mathrm{P}>0.05)$. No bleeding outcome categorizations at study completion differed between the two study groups (Table 3).

Over the duration of follow-up, nearly one-half (46.8\%) of patients were hospitalized due to gastrointestinal bleeding, with a length of stay of $10.7 \pm 15.5$ days. One-half of patients also required blood transfusions over that time, with a mean of almost three units of blood transfused $(2.9 \pm 5.0$ units) per patient. Most $(83.3 \%)$ patients also required iron supplementation (Table 4). Again, there were no significant differences between the study groups.

Endoscopic treatment was performed in $7.7 \%$ of patients (three of 39) at the initial procedure, which was, of course, only applicable to patients having been randomly assigned to $\mathrm{PE}$.

Patient satisfaction was assessed after undergoing the study procedure (Table 5). While patient satisfaction was uniformly very high, there was a significant difference in satisfaction with office wait times between patients undergoing VCE and PE (91.4\% versus $67.7 \%$; $\mathrm{P}<0.05)$.

More than one-third (35.4\%) of patients crossed over due to ongoing bleeding. Crossovers occurred significantly more often toward VCE: that is, among those who were originally randomly assigned to undergo PE (22.5\% versus 48.7\%; P=0.01). Significantly more lesions were detected by VCE in patients initially randomly assigned to PE than vice versa $(10.0$ versus $35.9 \%$; $<0.01)$. After considering crossovers, overall lesion detection rates did not differ between VCE-first and PE-first groups (75.0\% versus $71.8 \%$; P not significant). Similarly, there was no difference in terms of identifying causes of bleeding (possible/certain: $79.3 \%$ versus $57.0 \%$; P not significant; certain: $17.2 \%$ versus $10.7 \%$; P not significant).
TABLE 5

Postprocedural patient satisfaction*

\begin{tabular}{lccc}
\hline Variable & VCE $(\mathbf{n}=\mathbf{4 0})$ & PE $(\mathbf{n}=\mathbf{3 9})$ & $\mathbf{P}$ \\
\hline Wait for appointment & 94.3 & 85.9 & 0.20 \\
Office wait time & 91.4 & 67.7 & $<0.05$ \\
Physician professionalism & 97.1 & 100.0 & 0.32 \\
Physician technical skills & 100.0 & 100.0 & $\mathrm{~N} / \mathrm{A}$ \\
Staff professionalism & 100.0 & 97.6 & 0.31 \\
Explanations & 100.0 & 100.0 & $\mathrm{~N} / \mathrm{A}$ \\
Overall & 100.0 & 100.0 & $\mathrm{~N} / \mathrm{A}$ \\
Comfort during procedure & 94.1 & 85.3 & 0.23 \\
Comfort after procedure & 94.1 & 85.3 & 0.23 \\
Willingness to repeat procedure & 100.0 & 100.0 & $\mathrm{~N} / \mathrm{A}$ \\
\hline
\end{tabular}

Data presented as \% unless otherwise indicated. *Excellent/very good versus good, fair or poor. N/A Not applicable; PE Push enteroscopy; VCE Video capsule endoscopy

In follow-up, after allowing for crossovers, endoscopic treatment rates (with PE) were noted in 5.0\% (two of 40) of those initially randomly assigned to VCE and 7.7\% (three of 39) among the PE group (ie, there were no additional treatments after the initial PE procedure in this latter group).

There were a total of five patients who, at the initial examination, were found to have lesions deemed to be a certain cause of OGIB. All were initially randomly assigned to VCE and all crossed over for potential endoscopic therapy. Two patients exhibited bleeding angiodysplasia lesions identified on VCE, one in the distal ileum and one at multiple sites. Neither underwent an endoscopic treatment on $\mathrm{PE}$ because in one case the endoscopist believed no treatment was necessary and in the other only a diverticulum could be identified at PE. A third patient had an ulcerated bleeding mass seen in the distal jejunum on VCE, but the lesion could not be reached on PE and underwent surgery. A fourth patient had an ulcerated, bleeding, stenosing lesion identified at the level of the mid-small bowel on VCE. On PE, a partially obstructing bleeding lesion was identified and biopsied. This lesion was found to be an adenocarcinoma; the patient underwent en bloc resection of portions of jejunum and transverse colon. The final patient was found to have active bleeding in the jejunum on VCE, without identification of a specific lesion. On crossover, the patient underwent electrocoagulation of the culprit lesions and remained bleed free thereafter.

Four patients (two in each group) required surgical intervention related to their gastrointestinal bleeding $(5.0 \%$ versus $5.1 \%$; P not significant), with no further rebleeding. One patient initially randomly assigned to VCE underwent en bloc resection of a T4 adenocarcinoma identified on VCE and biopsied on subsequent PE, as described above. Another patient (randomly assigned to PE) underwent right hemicolectomy for a cecal adenocarcinoma that was originally missed on prestudy colonoscopy. A third patient (randomly assigned to PE) underwent a nondiagnostic intraoperative enteroscopy but did not rebleed. The final of these four patients (randomly assigned to PE) underwent small bowel resection for an undetermined benign lesion at another hospital and completed the study.

While mortality was significantly higher in the VCE group $(10.0 \%$ versus $0.0 \% ; \mathrm{P}=0.04)$, none of these deaths could be directly attributed to VCE or to gastrointestinal bleeding (one due to hepatic failure, one due to bladder cancer, two due to renal cancer).

\section{DISCUSSION}

VCE has become the recommended imaging modality of choice in OGIB patients after a negative gastroscopy and colonoscopy (5), certainly in patients with inactive bleeding (6), with a favourable cost-effectiveness profile $(13,14)$.

A meta-analysis by Triester et al (7) showed that VCE was superior to $\mathrm{PE}$, small bowel follow-through, computed tomography enteroclysis and magnetic resonance imaging with respect to detection of a bleeding 
source in OGIB. A head-to-head comparison even confirmed VCE to be as good as intraoperative enteroscopy with respect to diagnostic yield (15). Comparative data regarding more contemporary deep enteroscopic methods (single-, double-balloon and spiral enteroscopy) were not widely available at the time.

In a meta-analysis of patients with iron deficiency anemia, Koulaouzidis et al (8) suggested that small bowel VCE provides a diagnotic yield reaching $66.6 \%$ (95\% CI $61.0 \%$ to $72.3 \%$ ) (8); in particular, more vascular, inflammatory, and mass or tumour lesions are detected. Recent RCTs assessing the diagnostic yields of VCE have focused on different types of small bowel endoscopic capsules with no one technology exhibiting superior results (16-18).

Limitations of these comparisons are the choice of diagnostic yield as outcome, rather than true, more downstream patient end points. An initial high-quality, true clinical outcomes trial by de Leusse et al (9) confirmed the diagnostic advantage of VCE over PE (50\% versus $25 \%$; $\mathrm{P}=0.02$ ), with a corresponding significant reduction in need for further imaging in patients investigated with VCE as first-line modality. However, overall diagnostic yield (after counting all crossovers), clinical outcomes and therapeutic impact did not differ between groups. A subsequent trial by Laine et al (10) found that VCE had a greater diagnostic yield than small bowel follow-through (30\% versus 7\% [difference $23 \%$ ]; $95 \%$ CI $11 \%$ to $36 \%$ ), although again, clinical outcomes including rebleeding, transfusion and hospitalization rates did not differ.

We report the first RCT trial to compare true clinical outcomes in patients with OGIB investigated initially by VCE or PE, with crossover dictated by clinical course, allowing for differentiation of the true clinical impact of each management approach. In fact, unlike the study by de Leusse et al (9), we compared clinical outcomes following a single diagnostic study (VCE versus PE) as opposed to an immediate crossover in the event of a negative initial study (VCE $\pm \mathrm{PE}$ versus $\mathrm{PE}$ \pm VCE). Moreover, patients were only allowed to crossover after the primary end point was reached and, in fact, only after ongoing bleeding was noted except if the index VCE identified a lesion requiring therapeutic PE (9). This is an important difference from the de Leusse et al (9) trial, given its study design (cross-over if negative study), analysis, and that study's high crossover rates in both directions $(50 \%$ and $76 \%$ ). These differences make it more difficult to draw conclusions about clinical outcomes that may not be attributed to a single investigation. The present report also differs from that of Laine et al (10) in that VCE is compared with PE as opposed to small bowel follow-through - an investigation that has recently fallen out of favour given its limited diagnostic yield (7). We believe our trial is, thus, more representative of a true clinical scenario and yields more clinically meaningful results, with its own limitations, of course, as discussed below. Our study population reflected a 'real-life' patient group with characteristics similar to other reports in that the patients had undergone numerous previous diagnostic studies, having been under investigation for an average of two years.

We found VCE to have a significantly better diagnostic yield than PE $(72.5 \%$ versus $48.7 \%$; $\mathrm{P}<0.05)$, consistent with previous reports (38\% to $93 \%$ for VCE) (19). Interestingly, a significant number of patients $(36.7 \%)$ were found to have lesions in the stomach, duodenum and colon - regions that are visualized by standard endoscopy, as has been previously noted $(5,6,13)$, leading to the recommendation that esophagogastroduodenoscopy and colonoscopy should be repeated whenever possible as part of the diagnostic workup, ideally immediately after an acute bleed (20). The cost effectiveness of this approach has more recently been questionned by some (21). Most (40.5\%) lesions were found in the jejunum and ileum, and VCE was significantly better than $\mathrm{PE}$ at visualizing lesions in these more distal regions not amenable to routine endoscopy ( $58 \%$ versus $13 \% ; \mathrm{P}<0.01$ ). A review of the recent literature suggests that small bowel disease is the cause of OGIB in $40 \%$ to $70 \%$ of cases (22-26).

Interestingly, lesions identified by VCE were more likely to be scored as possible or certain sources of OGIB (79.3\% versus $35.0 \%$; $\mathrm{P}<0.01$ ), as has been previously reported, especially in older patients
$(24,25,27)$. Although VCE has a diagnostic advantage, PE can be used as both a diagnostic and therapeutic tool. However, despite the fact that one-half of patients who underwent PE had lesions identified as a possible source of OGIB, only $7.7 \%$ underwent any intervention. Moreover, despite the therapeutic advantage of $\mathrm{PE}$, more patients crossed over to VCE than to PE. In fact, only $22.5 \%$ of patients who crossed over after initial VCE study (and 5.0\% of all patients initially randomly assigned to VCE) underwent any endoscopic treatment. These findings merit consideration and likely reflect the limited accessibility of distal small bowel lesions by PE, and the nature of the identified lesions that may not be judged to be a cause of OGIB, at least in a population with a mix of occult and overt bleeding similar to that observed in our and most trials. Endoscopic intervention is associated with a $27 \%$ to $85 \%$ success rate with respect to prevention of further OGIB (27). However the contribution of any therapeutic intervention is difficult to assess when the majority of untreated individuals also do not experience any further $\operatorname{OGIB}(9,10)$. In fact, it is the hope that future research can lead to improved selection of patients, such as those with overt bleeding $(5,6,28)$, and that endoscopic recognition of lesions is required to optimize the downstream impact of any VCE findings.

While PE was the diagnostic test of choice at the time of the study, new endoscopic techniques, namely deep enteroscopy (single balloon, double balloon, spiral enteroscopy) are evolving and may represent signficant improvements over PE (6). It has been reported that PE can only visualize approximately one-third of the small bowel, providing a diagnosis in less than one-half of cases of OGIB (29-31). A recent meta-analysis by Teshima et al (32) showed similar diagnostic yields for VCE and double balloon enteroscopy (62\% versus 56\%, respectively); with improved double-balloon enteroscopy yield when performed in patients with a positive VCE (OR 1.79 [95\% CI 1.09 to 2.96]). It may be that the optimal role of VCE is to select patients who will then undergo further therapeutic intervention using contemporary, more effective deep enteroscopic therapeutic techniques.

While it could be argued that our RCT was underpowered to detect differences in clinical outcomes, our results match those found in the literature $(9,10)$. Although representative, the patients' duration of symptoms (despite recent recurrence or persistence of bleeding within six months of randomization) may have influenced the results. Indeed, recent data suggest a greater yield for investigation initiated soon after an episode of bleeding (33). It has been noted that the diagnostic yield of VCE is higher in patients with overt rather than occult OGIB (33), even more so during or soon after an active bleed $(15,34)$. Importantly, Leung et al $(28)$ recently reported an RCT of 60 patients with overt OGIB with mean follow-up of 48.5 months. The diagnostic yield of performing an immediate VCE was significantly higher than that of an urgent angiography (53.3\% versus $20.0 \% ; \mathrm{P}=0.016$ ), but the cumulative rates of rebleeding in the angiography and VCE group were $33.3 \%$ and $16.7 \%$, respectively $(\mathrm{P}=0.10)$; again raising questions about the clinical pertienence of many of the findings.

Other criticisms could include the generalizability of the patient population. In fact, patients had experienced symptoms, on average, for two years. Furthermore, there was a low recent ongoing intake of nonsteroidal anti-inflammatory drugs, probably consistent with the chronicity of symptoms and discontinuation of such possible offending medications. The low intervention rate noted also emphasizes the chronicity of symptoms in most of these patients.

We believe the present RCT more clearly characterizes the diagnostic impact of endoscopic findings on subsequent clinical management than previously. The findings suggest a higher diagnostic yield for VCE compared with $\mathrm{PE}$, but with no significant alterations in bleeding outcomes or health care utilization over a 12-month follow-up period. Additional high-quality RCTs, perhaps focusing on patients with overt bleeding while better characterizing the appearance of endoscopic lesions that bear true prognostic significance, in association with the use of contemporary deep enteroscopic techniques, are needed. 
AUTHOR CONTRIBUTIONS: Conception and design of the study: Alan N Barkun, Pascal Burtin and Myriam Martel. Generation, collection, assembly, analysis and/or interpretation of data: Alan N Barkun, Dev S Segarajasingam, Stephen C Hanley, Kevin A Waschke, Pascal Burtin, Josée Parent, Serge Mayrand, Carlo A Fallone, Gilles Jobin, Ernest G Seidman and Myriam Martel. Drafting or revision of the manuscript: Alan N Barkun, Dev S Segarajasingam, Stephen C Hanley, Kevin A Waschke, Pascal Burtin, Josée Parent, Serge Mayrand, Carlo A Fallone, Gilles Jobin, Ernest G Seidman and Myriam Martel. Approval of the final version of the manuscript: Alan N Barkun, Dev S Segarajasingam, Stephen C Hanley, Kevin A Waschke, Pascal Burtin, Josée Parent, Serge Mayrand, Carlo A Fallone, Gilles Jobin, Ernest G Seidman and Myriam Martel.

\section{REFERENCES}

1. Lewis BS. Small intestinal bleeding. Gastroenterol Clin North Am 2000;29:67-95, vi.

2. Zuckerman GR, Prakash C, Askin MP, Lewis BS. AGA technical review on the evaluation and management of occult and obscure gastrointestinal bleeding. Gastroenterology 2000;118:201-21.

3. Foutch PG, Sawyer R, Sanowski RA. Push-enteroscopy for diagnosis of patients with gastrointestinal bleeding of obscure origin. Gastrointest Endosc 1990;36:337-41.

4. Flickinger EG, Stanforth AC, Sinar DR, MacDonald KG, Lannin DR, Gibson JH. Intraoperative video panendoscopy for diagnosing sites of chronic intestinal bleeding. Am J Surg 1989;157:137-44.

5. Raju GS, Gerson L, Das A, Lewis B. American Gastroenterological Association (AGA) Institute medical position statement on obscure gastrointestinal bleeding. Gastroenterology 2007;133:1694-6.

6. Fisher L, Lee Krinsky M, Anderson MA, et al. The role of endoscopy in the management of obscure GI bleeding. Gastrointest Endosc 2010;72:471-9.

7. Triester SL, Leighton JA, Leontiadis GI, et al. A meta-analysis of the yield of capsule endoscopy compared to other diagnostic modalities in patients with obscure gastrointestinal bleeding. Am J Gastroenterol 2005;100:2407-18.

8. Koulaouzidis A, Rondonotti E, Giannakou A, Plevris JN. Diagnostic yield of small-bowel capsule endoscopy in patients with iron-deficiency anemia: A systematic review. Gastrointest Endosc 2012;76:983-92.

9. de Leusse A, Vahedi K, Edery J, et al. Capsule endoscopy or push enteroscopy for first-line exploration of obscure gastrointestinal bleeding? Gastroenterology 2007;132:855-62.

10. Laine L, Sahota A, Shah A. Does capsule endoscopy improve outcomes in obscure gastrointestinal bleeding? Randomized trial versus dedicated small bowel radiography. Gastroenterology 2010;138:1673-1680 e1; quiz e11-2.

11. Pennazio M, Eisen G, Goldfarb N. ICCE consensus for obscure gastrointestinal bleeding. Endoscopy 2005;37:1046-50.

12. Ell C, Remke S, May A, Helou L, Henrich R, Mayer G. The first prospective controlled trial comparing wireless capsule endoscopy with push enteroscopy in chronic gastrointestinal bleeding. Endoscopy 2002;34:685-9.

13. Ladas SD, Triantafyllou K, Spada C, et al. European Society of Gastrointestinal Endoscopy (ESGE): Recommendations (2009) on clinical use of video capsule endoscopy to investigate small-bowel, esophageal and colonic diseases. Endoscopy 2010;42:220-7.

14. Marmo R, Rotondano G, Rondonotti E, et al. Capsule enteroscopy vs. other diagnostic procedures in diagnosing obscure gastrointestinal bleeding: A cost-effectiveness study. Eur J Gastroenterol Hepatol 2007;19:535-42.

15. Hartmann D, Schmidt H, Bolz G, et al. A prospective two-center study comparing wireless capsule endoscopy with intraoperative enteroscopy in patients with obscure GI bleeding. Gastrointest Endosc 2005;61:826-32.

16. Dolak W, Kulnigg-Dabsch S, Evstatiev R, et al. A randomized head-to-head study of small-bowel imaging comparing MiroCam and EndoCapsule. Endoscopy 2012;44:1012-8.

17. Choi EH, Mergener K, Semrad C, et al. A multicenter, prospective, randomized comparison of a novel signal transmission capsule endoscope to an existing capsule endoscope. Gastrointest Endosc 2013;78:325-332.
FUNDING: Support from the American Society for Gastrointestinal Endoscopy, American College of Gastroenterology, and Canadian Institutes for Health Research. Support for DS Segarajasingam from the University of Western Australia Overseas Medical Fellowships (Eva KA Nelson). Dr EG Seidman is supported by a Canada Research Chair.

DISCLOSURES: Dr AN Barkun is a consultant for Olympus. Dr EG Seidman has received research study support, is on the medical advisory board and speakers' bureau for Given Imaging Inc. Dev S Segarajasingam, Stephen C Hanley, Kevin A Waschke, Pascal Burtin, Josée Parent, Serge Mayrand, Carlo A Fallone, Gilles Jobin and Myriam Martel have no conflicts of interests to declare related to this article.

18. Pioche M, Vanbervliet G, Jacob P, et al. Prospective randomized comparison between axial- and lateral-viewing capsule endoscopy systems in patients with obscure digestive bleeding. Endoscopy 2014;46:479-84.

19. Tang SJ, Haber GB. Capsule endoscopy in obscure gastrointestinal bleeding. Gastrointest Endosc Clin N Am 2004;14:87-100.

20. Cooper GS, Kou TD, Wong RC. Use and impact of early endoscopy in elderly patients with peptic ulcer hemorrhage: A populationbased analysis. Gastrointest Endosc 2009;70:229-35.

21. Rondonotti E, Marmo R, Petracchini M, de Franchis R, Pennazio M. The American Society for Gastrointestinal Endoscopy (ASGE) diagnostic algorithm for obscure gastrointestinal bleeding: Eight burning questions from everyday clinical practice. Dig Liver Dis 2013;45:179-85.

22. Mylonaki M, Fritscher-Ravens A, Swain P. Wireless capsule endoscopy: A comparison with push enteroscopy in patients with gastroscopy and colonoscopy negative gastrointestinal bleeding. Gut 2003;52:1122-6.

23. Ginsberg GG, Barkun AN, Bosco JJ, et al. Wireless capsule endoscopy: August 2002. Gastrointest Endosc 2002;56:621-4.

24. Tacheci I, Deviere J, Kopacova M, Douda T, Bures J, Van Gossum A. The importance of upper gastrointestinal lesions detected with capsule endoscopy in patients with obscure digestive bleeding. Acta Gastroenterol Belg 2011;74:395-9.

25. Jensen DM. Current diagnosis and treatment of severe obscure GI hemorrhage. Gastrointest Endosc 2003;58:256-66.

26. Levi Z, Gal E, Vilkin A, Chonen Y, Belfer RG, Fraser G, Niv Y. Fecal immunochemical test and small bowel lesions detected on capsule endoscopy: Results of a prospective study in patients with obscure occult gastrointestinal bleeding. Eur J Gastroenterol Hepatol 2011;23:1024-8.

27. Raju GS, Gerson L, Das A, Lewis B. American Gastroenterological Association (AGA) Institute technical review on obscure gastrointestinal bleeding. Gastroenterology 2007;133:1697-717.

28. Leung WK, Ho SS, Suen BY, et al. Capsule endoscopy or angiography in patients with acute overt obscure gastrointestinal bleeding: A prospective randomized study with long-term follow-up. Am J Gastroenterol 2012;107:1370-6.

29. Landi B, Tkoub M, Gaudric M, et al. Diagnostic yield of push-type enteroscopy in relation to indication. Gut 1998;42:421-5.

30. Pennazio M, Arrigoni A, Risio M, Spandre M, Rossini FP. Clinical evaluation of push-type enteroscopy. Endoscopy 1995;27:164-70.

31. Bouhnik Y, Bitoun A, Coffin B, Moussaoui R, Oudghiri A, Rambaud JC. Two way push videoenteroscopy in investigation of small bowel disease. Gut 1998;43:280-4.

32. Teshima CW, Kuipers EJ, van Zanten SV, Mensink PB. Double balloon enteroscopy and capsule endoscopy for obscure gastrointestinal bleeding: An updated meta-analysis. J Gastroenterol Hepatol May 2011;26:796-801.

33. Yamada A, Watabe H, Kobayashi Y, Yamaji Y, Yoshida H, Koike K. Timing of capsule endoscopy influences the diagnosis and outcome in obscure-overt gastrointestinal bleeding. Hepatogastroenterology 2012;59:676-9.

34. Pennazio M, Santucci R, Rondonotti E, et al. Outcome of patients with obscure gastrointestinal bleeding after capsule endoscopy: Report of 100 consecutive cases. Gastroenterology 2004;126:643-53. 


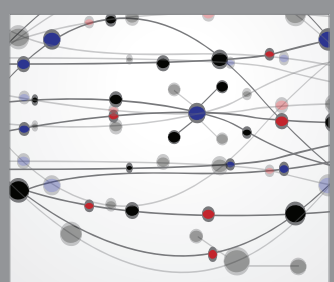

The Scientific World Journal
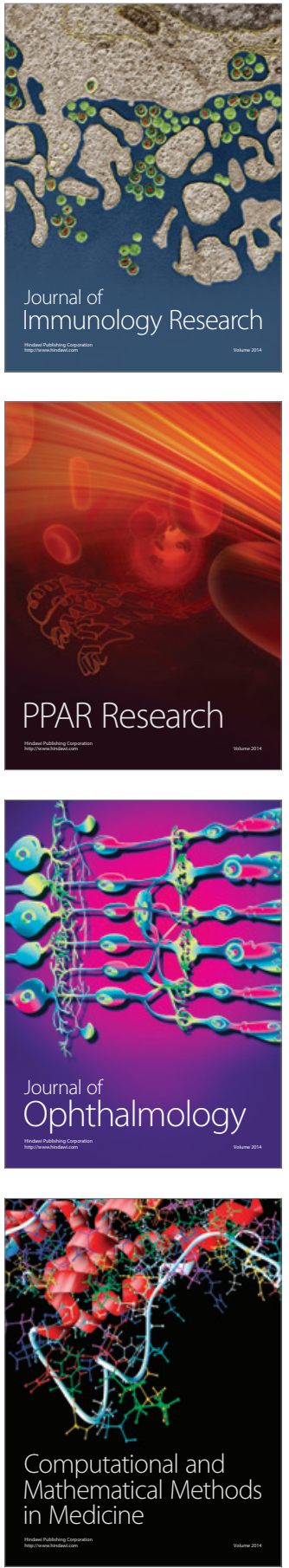

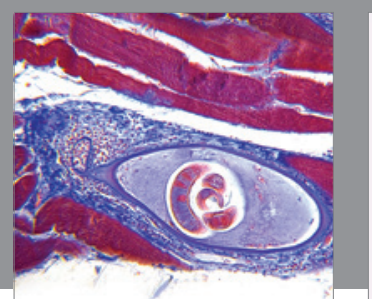

Gastroenterology Research and Practice

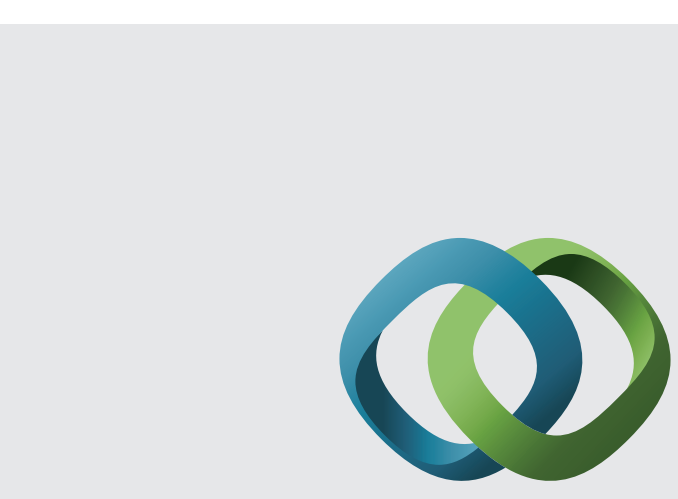

\section{Hindawi}

Submit your manuscripts at

http://www.hindawi.com
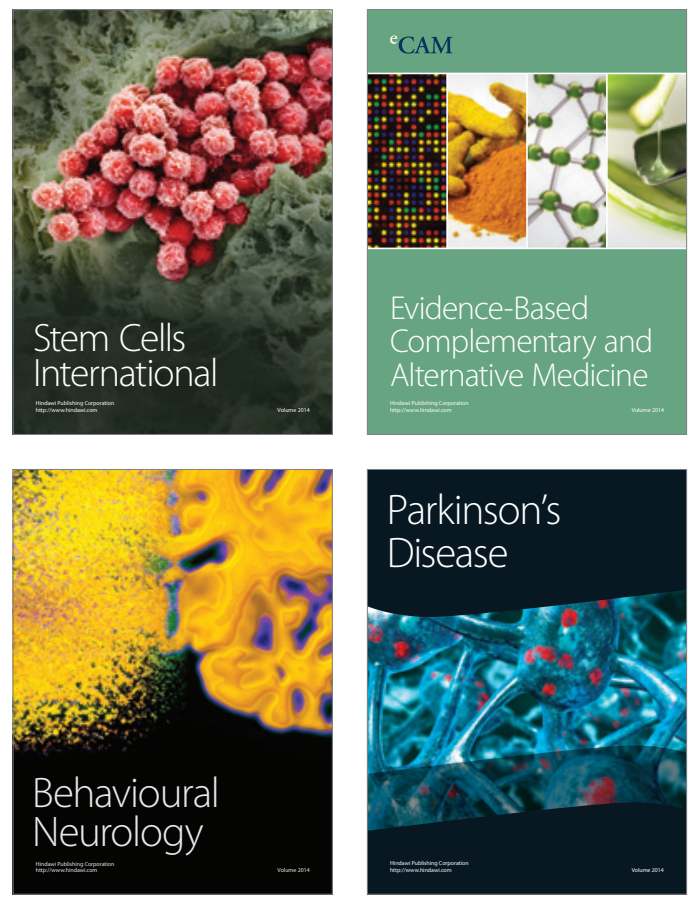
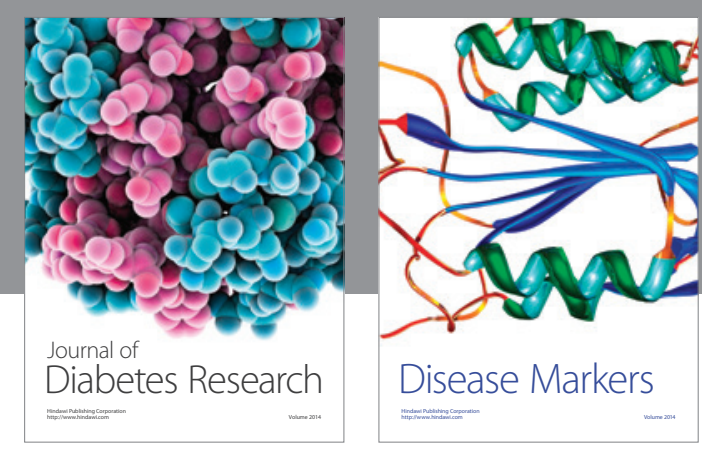

Disease Markers
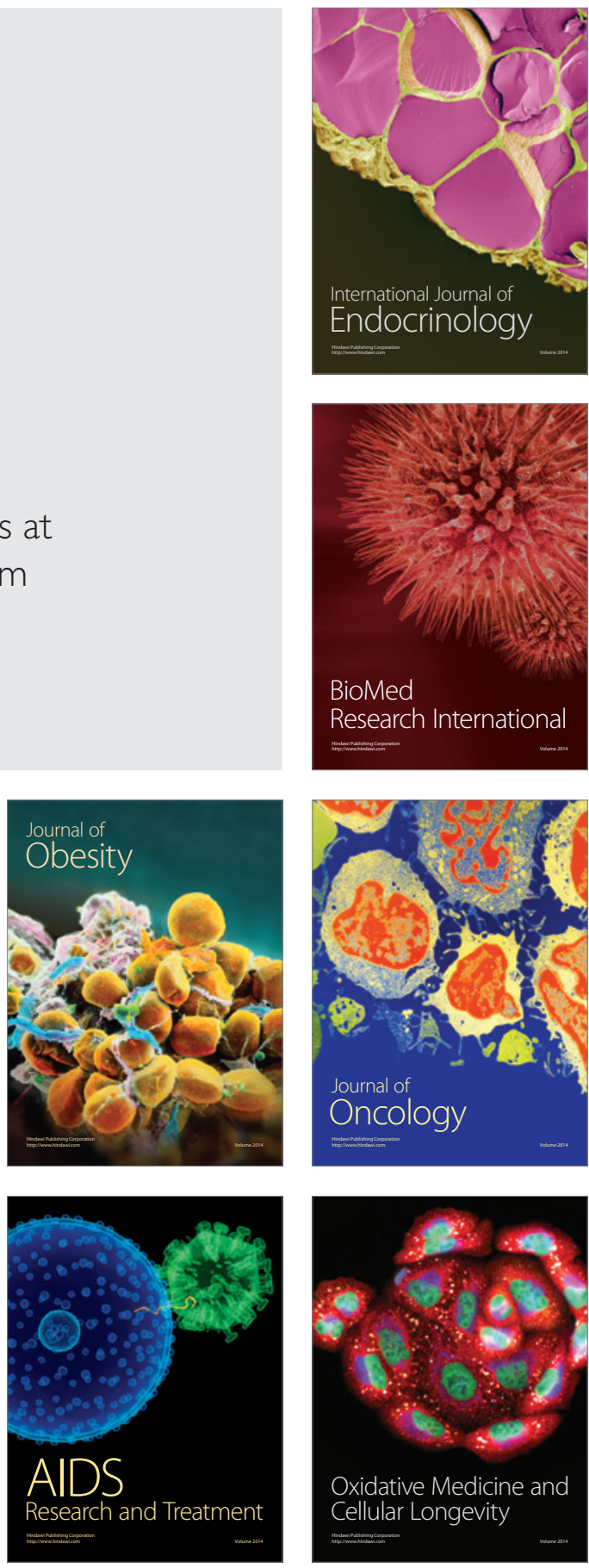